\title{
Nanomechanical characterization and modeling of anodized porous aluminum oxide thin films with photografted anti-biofouling polymer brushes on their pore walls
}

\author{
Hamzah Bakhti $^{1,2} \cdot$ Ayoub Laghrissi $^{1} \cdot$ Artjom Roth $^{1} \cdot$ Lahcen Azrar $^{2} \cdot$ Mohammed Es-Souni $^{1}$ (D)
}

Received: 28 January 2020 / Accepted: 3 March 2020 / Published online: 20 March 2020

(c) The Author(s) 2020

\begin{abstract}
Nanocomposites are known for their unique properties with many potential applications. In the present work, porous anodic aluminum oxide (AAO) thin films were processed on glass substrates and subsequently photo-grafted with a zwitterionic anti-biofouling polymer. This allows to fabricate scratch-resistant, transparent anti-biofouling films. The microstructure and how it is affected by nanomechanical testing are investigated by scanning electron microscopy and atomic force microscopy. It is shown that the polymer forms a thin layer on the pore walls and in deionized water, the pore diameter changes due to swelling of the polymer. The nanomechanical and scratch resistance properties are studied using a nanoindenter testing system. The experimental results are validated via numerical calculations. The values of the elastic modulus and hardness are shown to be in good agreement with the numerical ones, and under dry conditions, higher values were obtained in comparison to wet films. There is also a large agreement between modeling and microscopic deformation behavior of the films. Finally, the critical loads in dry and wet conditions for the non-coated AAO samples are approximately the same, while for the coated samples, the critical load is reached rapidly in wet condition in comparison to the dry one.
\end{abstract}

Keywords Nanoindentation $\cdot$ Anodized porous aluminum oxide $\cdot$ Computational modeling $\cdot$ Mechanical properties $\cdot$ Polymer brushes

\section{Introduction}

Porous anodic aluminum oxide (AAO) is widely used for the template-assisted processing of nanomaterials (Xie et al. 2016; Mijangos et al. 2016). The structural features like the pore length, diameter, and density (Balde et al. 2015; Berger et al. 2016a; Sharma and Islam 2016; Chung et al. 2017; Laghrissi and Es-Souni 2019) can be controlled via a proper choice of the anodization conditions and electrolyte, and are transferred to the nanostructures, because the pores are the

Electronic supplementary material The online version of this article (https://doi.org/10.1007/s13204-020-01338-6) contains supplementary material, which is available to authorized users.

Mohammed Es-Souni

mohammed.es-souni@fh-kiel.de

1 Institute for Materials and Surface Technology (IMST), University of Applied Sciences, 24149 Kiel, Germany

2 M2CS, STIS Research Center, ENSET, Mohammed V University, 10100 Rabat, Morocco molds in which the nanostructures are grown. More applications of AAO include photonic crystals (Wang et al. 2007), the structural stabilization of polymeric films (Szuwarzyński et al. 2013), and corrosion protection (Wojciechowski et al. 2016; Yabuki et al. 2019). Recently, AAO films on glass substrate were shown to be used as structural stabilization scaffolds for anti-biofouling polymers, yielding transparent, scratch-resistant films which resist protein and cell adhesion; in particular, the polymer thin films were shown to not only cover the surface but also adhere to the pore walls thus allowing self-healing of the anti-fouling surface (Wassel et al. 2018). However, a quantitative analysis of the nanomechanical properties of the films and their scratch resistance is still to be performed, to fully characterize the films and understand the ensuing behavior.

The experimental characterization by nanoindentation technology has evolved in the last decade to a powerful tool to determine the nanomechanical properties of thin films grown on different substrates (Hu 2017; Wen et al. 2017) thanks to advanced capabilities and the improved post-analysis of the continuously measured depth, load and stiffness 
values. For instance, the experimental method of continuous stiffness measurement (CSM) coupled with the Oliver and Pharr analysis, (Oliver and Pharr 1992, 2004), allows the calculation of the nanomechanical properties as a function of the depth or the load during the nanoindentation process ( $\mathrm{Li}$ and Bhushan 2002; Hu 2017). Indentation size effects on elastic modulus and hardness of $\mathrm{MgB}_{2}$ thin film were investigated by Ozmetin et al. (Ozmetin et al. 2015). In another work, Mallikarjunachari and Pijush Ghosh used nanoindentation and scratch testing techniques in the analysis of strength and mechanical response of polymer thin film interfaces (Mallikarjunachari and Ghosh 2016).

In terms of what is of concern to this work, various studies on the mechanical properties of AAO can be found in the literature, including the effects of pore size and pore density on the elastic modulus and hardness (Ko et al. 2005; Tsyntsaru et al. 2014; Dai et al. 2017). However, very few studies were conducted so far on coated AAO to investigate the difference between the mechanical characteristics of bare and coated pores. Apart from one work on polydimethylsiloxane filled AAO membranes (Fang et al. 2009), and another one on metal filled AAO (Zechner et al. 2014), no other work has been found on the nanomechanical properties of polymerAAO thin film composites.

Modeling and finite element analysis (FEA) is of a great benefit for the prediction and simulation of the mechanical properties of various types of materials, and in particular, thin film coatings (Khan et al. 2018; Alaboodi and Hussain 2019). Furthermore, a deeper understanding of the nanoindentation process can be approached by studying the stress and strain distributions in the film and the substrate, which hardly can be analyzed by experimental means. For AAO thin films, Hu et al. developed a three-dimensional FE model to study the mechanical characteristics of the films, and to identify the effect of the glass substrate (Hu et al. 2016).

Further, nano-scratch testing provides an additional tool for the characterization of thin film coatings, particularly their adhesion strength to the substrate. Few studies associated with scratch testing of AAO films on aluminum are reported in the literature (Vojkuvka et al. 2012; Choudhary et al. 2015), with emphasis on their mechanical characteristics and the scratch track morphology as a function of the anodization conditions.

In this paper, $500 \mathrm{~nm}$ thick AAO films were obtained via anodization of a thin aluminum film on a glass substrate and subsequently coated with a non-fouling, zwitterionic polymer, namely poly (sulfobetaine methacrylate), N,Ndimethyl-N-(2-methacryloyloxyethyl-N-(3-sulfopropyl) ammonium betaine (SPE), using a photografting technique as described in previous work (Es-Souni et al. 2019). Their nanomechanical properties are investigated using a nanoindenter device and compared to those of non-coated AAO films. The resulting elastic modulus and hardness are compared and validated with a three-dimensional FEA model. The nanomechanical characteristics were further analyzed in dry and wet conditions in anticipation of their behavior in service. Nano-scratch testing is also performed on the coated and non-coated thin films in wet and dry conditions, where the scratch profile and cross profile are obtained. Finally, the surface morphology of the nanomechanically tested samples is analyzed and discussed with the aid of SEM imaging.

\section{Experiment}

\section{SPE-coated AAO thin films preparation}

The processing of SPE-coated AAO thin films on glass substrate is shown in Scheme 1, following the procedure presented in previous works (Berger and Es-Souni 2016; Laghrissi and Es-Souni 2019; Es-Souni et al. 2019). A $500 \mathrm{~nm}$ aluminum film was deposited on a heterostructure
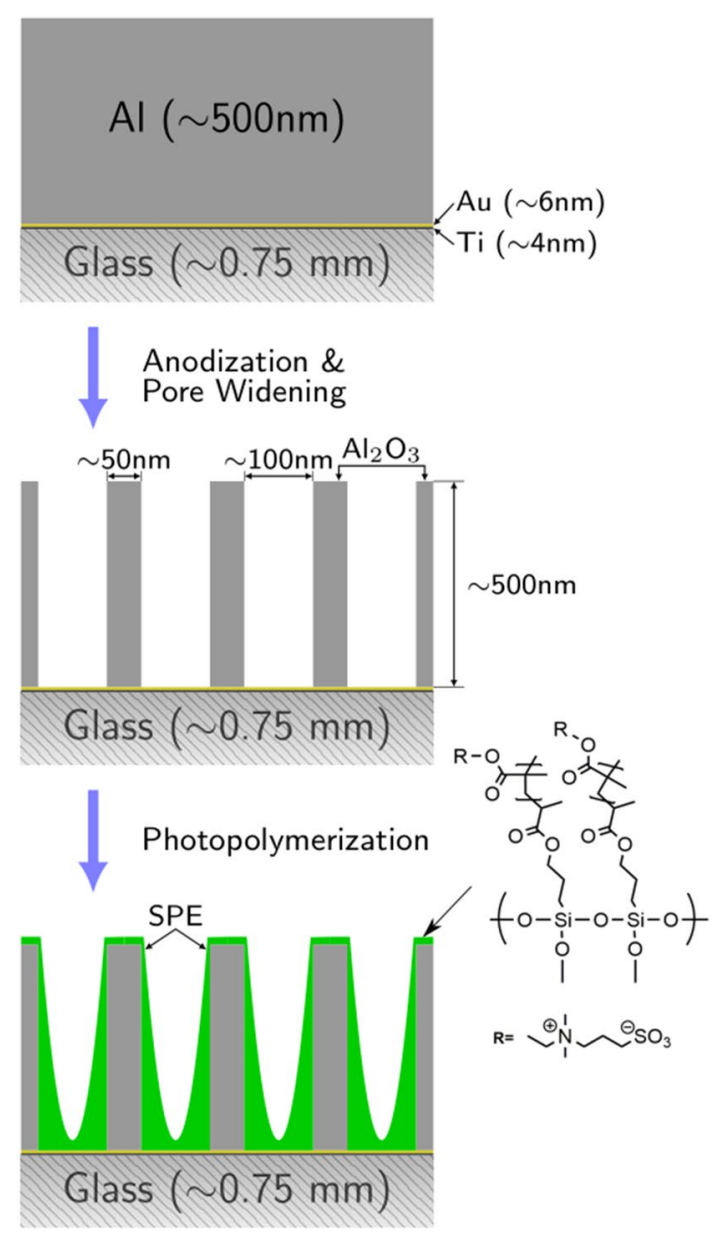

Scheme 1 Schematic representation of the fabrication procedure of SPE-coated AAO thin films on glass substrate 
of $\mathrm{Au}(6 \mathrm{~nm}) / \mathrm{Ti}(4 \mathrm{~nm}) / \mathrm{glass}$ using electron beam evaporation in a PVD device (PVD75, Lesker, USA). The anodization process is conducted using a two-electrode set-up in $0.2 \mathrm{M}$ aqueous solution of oxalic acid under potentiostatic conditions of $70 \mathrm{~V}$ using an electrochemical workstation (Keithley 2400 SM, Cleveland, OH, USA). A Pt foil was used as a counter electrode. Phosphoric acid (5 wt\% in water) was used for the barrier layer removal and pore widening for $50 \mathrm{~min}$ at $30{ }^{\circ} \mathrm{C}$. The average thickness of the AAO layer is about $500 \mathrm{~nm}$ and the substrate thickness is $0.75 \mathrm{~mm}$.

The dimensions of the AAO pores were statistically evaluated in a previous work (Berger et al. 2016b) and as shown in Fig. S1 (Supplementary Material), the average pore diameter is in the range of 123-140 $\mathrm{nm}$ for a minimum opening time between 44 and 48 min with standard deviation of $15 \%$, while, the distance between the center points of two adjacent pores is $156 \mathrm{~nm}$ with standard deviation of $10 \%$.

For the coating, a photo-grafting process following the procedure described in earlier work (Es-Souni et al. 2019) was conducted to fill the pores with a zwitterionic polymer, Poly (sulfobetaine methacrylate), N,N-dimethyl-N(2-methacryloyloxyethyl-N-(3-sulfopropyl)ammonium betaine (SPE).

Microscopic characterization of the films was performed using a high-resolution scanning electron microscopy (SEM Ultra Plus, ZEISS, Germany) operating in the secondary (SE) and energy selective backscattered (ESB) electron modes. The SEM is also equipped with an energy dispersive X-ray spectroscopy (EDS) package (INCAx-act, Oxford Instruments, UK). The surface morphology was also investigated using an atomic force microscope (AFM, Nanowizard, JPK, Berlin, Germany).

\section{Characterization by nanoindentation}

Experimental characterization of the samples was performed using iMicro ${ }^{\circledR}$, Nanomechanics Inc., a nanoindentation and nanoscratch testing system (KLA Tencor, Oak Ridge, TN, USA) mounted on an adaptive stage for vibration damping. The iMicro system offers a variety of analytic models that can be utilized to determine the properties of various materials using the force, displacement and stiffness data obtained from indentation or scratch tests.

A Berkovich pyramidal sharp-tip indenter was used in the measurements to obtain the load-depth curves. Fig. S2a (Supplementary Material) shows a sketch of a perfect Berkovich tip geometry which is a three-sided pyramid with an angle of $65.27^{\circ}$ between the vertical axis and the one of the pyramid faces, while the actual average measured values are $65.25 \pm 0.3^{\circ}, 65.23^{\circ} \pm 0.3$ and $65.29 \pm 0.3^{\circ}$ with respect to each pyramid face. The three faces are symmetrical in a cyclic way around the vertical axis with $120^{\circ}$ between each other, and the average measured angle is also $120^{\circ} \pm 0.1$. A SEM image of an indent using the described Berkovich tip is shown in Fig. $\mathrm{S} 2 \mathrm{~b}$ on aluminum. Due to the imperfection of the diamond tip, whether in the face angles or the tip rounding, an advanced tip calibration procedure was followed by performing indentation tests on fused silica. The resulting data were used to obtain an interpolation of the relationship between the contact depth, hc and the area, Ac, given in a 7-terms polynomial as follows:

$$
\begin{aligned}
\mathrm{A}_{\mathrm{c}}= & 24.5 \mathrm{~h}_{\mathrm{c}}^{2}-16834.98 \mathrm{~h}_{\mathrm{c}}+2475336.65 \mathrm{~h}_{\mathrm{c}}^{0.5} \\
& -51810470.24 \mathrm{~h}_{\mathrm{c}}^{0.25}+301436327.43 \mathrm{~h}_{\mathrm{c}}^{0.125} \\
& -582192243.25 \mathrm{~h}_{\mathrm{c}}^{0.0625}+330194978.12 \mathrm{~h}_{\mathrm{c}}^{0.03125}
\end{aligned}
$$

Using a test method adapted for thin films, the elastic modulus and hardness are measured as a continuous function of the penetration depth. The method is based on the continuous stiffness measurement (CSM) by applying small superposed oscillation with a fixed frequency and amplitude values of $100 \mathrm{~Hz}$ and $2 \mathrm{~nm}$, respectively. In the thin film method, the loading process stops at $50 \%$ of the film thickness, but the results are calculated for $25 \%$ of that thickness, to minimize the substrate effect. In our case, the thickness is $500 \mathrm{~nm}$. Thus, the indentation stops at the depth of $250 \mathrm{~nm}$, and the properties are calculated for the indentation depth of $125 \mathrm{~nm}$. The reduced modulus, $E_{\mathrm{r}}$, of the sample is obtained using the classical Oliver and Pharr analysis (Oliver and Pharr 1992, 2004). The elastic modulus, $E$, of the coated and non-coated AAO thin film samples can then be obtained from the following equation (Oliver and Pharr 1992, 2004):

$\frac{1}{E_{\mathrm{r}}}=\frac{1-v^{2}}{E}+\frac{1-v_{i}^{2}}{E_{i}}$

where $E_{i}=1141$ and $\nu_{i}=0.07$ are, respectively, the elastic modulus and Poisson's ratio of the diamond tip of the indenter, while, $\nu=0.21$ is the Poisson's ratio of the films. Dynamical testing on the glass substrate was also conducted prior to the thin film samples by performing normal indentation tests with a maximum load of $50 \mathrm{mN}$. The Poisson's ratio of the glass substrate used to calculate the elastic modulus is $\nu_{s}=0.22$.

Further, to check the homogeneity of the properties, the hardness and elastic modulus of the SPE-coated and noncoated AAO thin films were mapped using Nanoblitz $4 \mathrm{D}^{\circledR}$, a high-speed mapping technique provided by iMicro nanoindenter system. The hardness and modulus maps were obtained by performing $20 \times 20$ indents on each of 20 layer depth in a two-dimensional square-grids of $10 \times 10 \mu \mathrm{m}^{2}$ and the tests were performed with a maximum indentation depth of $200 \mathrm{~nm}$.

\section{Nano-scratch testing}

Controlled scratch tests were performed on the SPE-coated and non-coated AAO thin films to study the adhesion of the coated thin films using the same Berkovich indenter with 
small load values on the film layer without reaching the substrate. The scratch test terminates if the indenter penetration reaches $80 \%$ of the film thickness, called the critical index. The test normally starts by profiling over the surface where the scratch will be performed. The length of the scratch is $100 \mu \mathrm{m}$ at a velocity of $5 \mu \mathrm{m} / \mathrm{s}$. The ramp-load takes place starting from $0 \mathrm{mN}$ and ending at a maximum value of $2 \mathrm{mN}$, if the critical index is not reached. The scratch vector is then profiled at the end of the scratch to record the residual damage from the scratch. Finally, the system performs cross profiling, which is a line profile orthogonal to the scratch vector. The length of the cross-profile is $50 \mu \mathrm{m}$ near the end of the scratch with a fraction of 0.8 of the scratch length and a velocity of $0.1 \mu \mathrm{m} / \mathrm{s}$.

\section{FE modeling}

A numerical model of the nanoindentation procedure was constructed using 3-D structural element type of the commercial ANSYS ${ }^{\circledR}$ 19.2. The proposed FE model was used to study the mechanical behavior of AAO thin films on glass substrate to validate the experimental results. A Berkovich indenter geometry was used with a round-shape at the tip of the indenter of $400 \mathrm{~nm}$ in length, to get the same depth-load results obtained after the calibration of the real tip used in the experiment, Fig. 1.

A bilinear isotropic model was used for the material properties of the glass substrate and AAO thin film to characterize the elasto-plastic deformations, while, an elastic isotropic model for the diamond indenter and the polymer coating was assumed to reduce computational time and cost. Young's modulus and Poisson's ratio used for the simulation are (73.12 Gpa, 0.22), for the glass substrate, (41.0 Gpa, 0.21), for the AAO film, $(100 \mathrm{kPa}, 0.3)$ for the SPE polymer and (1141 GPa, 0.07) for the diamond. The yield strength values for glass and AAO are chosen by adapting an optimization technique to adjust the maximum load value to the obtained experimental data, resulting in $Y_{\mathrm{s}}=4.6 \mathrm{GPa}$ for glass and $Y_{\mathrm{f}}=1.66 \mathrm{GPa}$ for AAO.

The dimensions of the three-dimensional model are set as $8 \mu \mathrm{m}$ in height and $8 \times 4 \mu \mathrm{m}$ in area, so the stress and strain contours will not reach the boundaries and hence will not be affected by the boundary conditions. As mentioned above, the AAO thickness is considered to be $500 \mathrm{~nm}$, with a mean pore diameter of $100 \mathrm{~nm}$, and a mean distance of $150 \mathrm{~nm}$ between each pore center. To reduce the cost of the numerical computation, an adaptive mesh of the proposed geometries was generated with refined mesh near the contact zones with the smallest element size about $0.03 \mu \mathrm{m}$, and a coarser mesh in other regions to reduce the number of

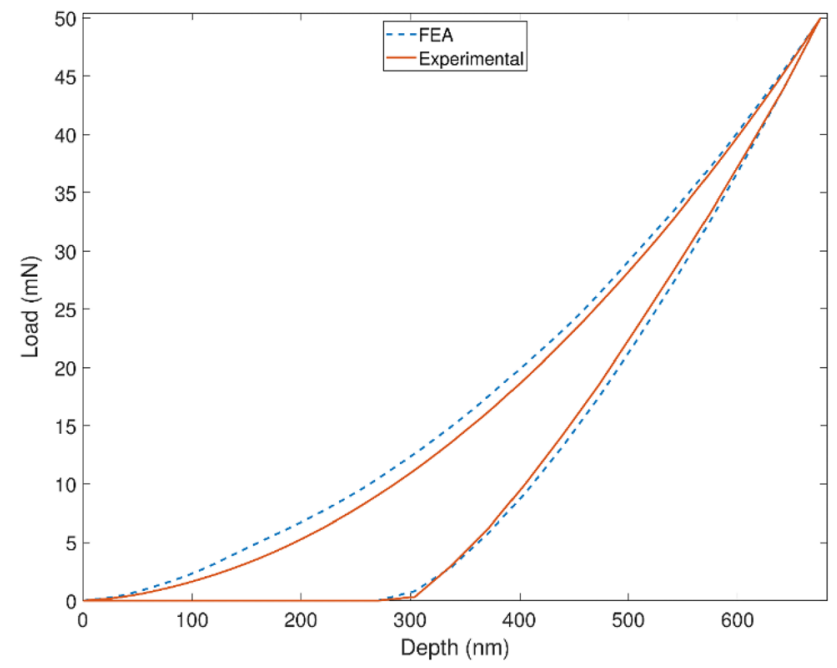

Fig. 1 Experimental and FEA load vs. depth curves of fused silica after calibration

elements used for the simulation. Examples of the meshed nanoindentation computation models with very close view of the intender round tip are shown in Fig. 2.

The solution was obtained by defining appropriate boundary conditions, namely, fixed support at the bottom nodes of the sample geometry, a loading and unloading indentation depths on the top of the indenter resembling the displacement values obtained from the experimental results. A symmetric plane at $z=0$ was assumed and the attached nodes were constrained with no displacements in $z$-axis direction $\left(u_{z}=0\right)$. The obtained load-depth curves were then analyzed following the same Oliver-Pharr analysis and the resulting values of the elastic modulus and hardness were compared with the values obtained from the experimental characterization.

\section{Results and discussion}

\section{Morphology of AAO layers}

The morphology of the AAO layers is depicted in Fig. 3a, b which shows top-view and cross-section SEM micrographs of the coated sample (the micrographs of the non-coated sample are shown in Fig. S3, supplementary information). Figure $3 b$ is a high-resolution back-scattered electron (BSE) micrograph of the cross-section of the coated sample; it illustrates that the polymer layer penetrates the pores and forms a thin layer of approximately $20-30 \mathrm{~nm}$ on the pore walls, because the AAO layer is transparent to the wave length used for the photografting $(360 \mathrm{~nm})$. An EDS analysis 


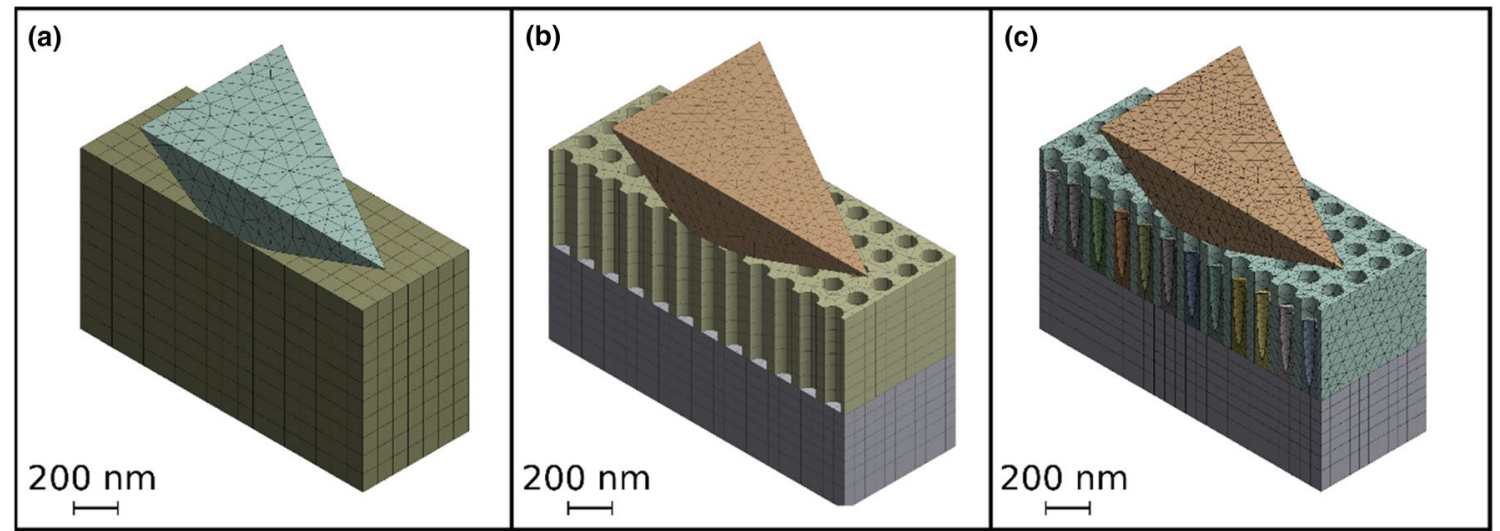

Fig. 2 Close view of 3-D meshed models of the nanoindentation modeling of glass (a), AAO on glass (b) and SPE-coated AAO on glass (c)

of the SPE-coated sample is also shown in Fig. 3c with both silicon (from the primer) and sulfur (as a signature of the SPE-coating) peaks together with the other elements present in the coating. The FT-IR spectra of the SPE-coated AAO films are shown in Fig. 3d which depicts the main vibrations pertaining to SPE (Es-Souni et al. 2019). These results are similar to those reported in earlier work together with a demonstration of the anti-biofouling properties of the films (Es-Souni et al. 2019).

Because anti-biofouling is one of the main applications sought for these films, AFM images were performed in deionized water which should hint to morphological changes in aqueous media. Figure $4 a, b$ are AFM images of the AAOSPE-coated films in dry (a) and wet condition (b), and show that some swelling takes place in water, changing the pore diameter. However, because of the low volume fraction of the polymer film and its weakness in terms of stiffness and strength values in comparison to the stronger AAO, the integrity of the film is not affected by swelling.

\section{Nanoindentation}

Table 1 shows the experimental data obtained from the nanoindentation tests on three samples, namely, glass substrate, non-coated AAO, and SPE-coated AAO thin films on glass substrate alongside with the corresponding standard deviations. Average values are calculated from 20 indents of the substrate and 24 indents on each of the bare AAO and SPE-coated AAO samples for both dry and wet conditions. The maximum load used in the experiments varies among the samples. For the glass substrate a $50 \mathrm{mN}$ load was applied, while for the coated and non-coated AAO thin films the maximum load is dependent on the thickness of the film, as the indentation terminates when the penetration depth reaches $50 \%$ of the film thickness.
Because the CSM method was used, the mechanical properties are reported with respect to the indentation depths. The results show small variations in the modulus and hardness values with respect to depth for the glass substrate with an average value of $77.15 \mathrm{GPa}$ for the elastic modulus and 4.75 GPa for the hardness which largely agree with results from literature (Hu et al. 2016). But for the AAO films, the modulus and hardness increase with increasing depth because of the substrate effect. The values of the elastic modulus and hardness obtained for the pure AAO thin film are $35.80 \mathrm{GPa}$ and $1.13 \mathrm{GPa}$, respectively, and are in good agreement with the values reported in the literature (Vojkuvka et al. 2012; Hemmouche et al. 2013). The SPE-coated AAO thin film shows similar elastic modulus and hardness values to the non-coated ones, mainly due to the low volume fraction of the polymer, and the fact that the stronger AAO film dominates the mechanical properties of the composite structure; this is confirmed by the FEA results below.

Because these films are intended for anti-biofouling applications, they were also tested after $24 \mathrm{~h}$ soaking in water at room temperature. The results obtained in this condition slightly differ from those pertaining to the dry condition, Table 2, which shows higher modulus and hardness values. Swelling of AAO and polymer (see also Fig. 4a, b) through incorporation of water molecules might account for this result.

\section{Mechanical property mapping}

Property mappings in a depth of $127 \mathrm{~nm}$ of the coated and non-coated AAO thin films are presented in Fig. 5. The maps were generated on an area of $100 \times 100 \mu \mathrm{m}^{2}$ by analyzing the results of $20 \times 20$ indents with a sufficient spacing to 
Fig. 3 Top-view (a) and crosssection (b) SEM micrographs of an SPE-coated AAO sample. The top-view (a) shows the SPE-coating surrounding the pore walls (arrows); some of the pores are entirely filled with the coating (arrows); the cross-section BSE micrograph (b) shows the gray polymer thin film on the pore walls (arrows); (c) EDS analysis of the SPE-coated AAO thin film showing the peaks constituting the thin film; silicon is from the primer-layer while sulfur is the signature of the SPE-layer. (d) FT-IR absorbance spectra of SPE on AAO obtained on different positions of the sample surface. It shows the sum spectrum (top) and enlarged views of $\mathrm{SO}_{3}$ (bottom, left), $\mathrm{CN}$ (bottom, middle) and $\mathrm{CO}$ (bottom, right) vibrations (Es-Souni et al. 2019).

The two vibrations centered at $1500 \mathrm{~cm}^{-1}$ are for carboxylated AAO (Wassel et al. 2018)
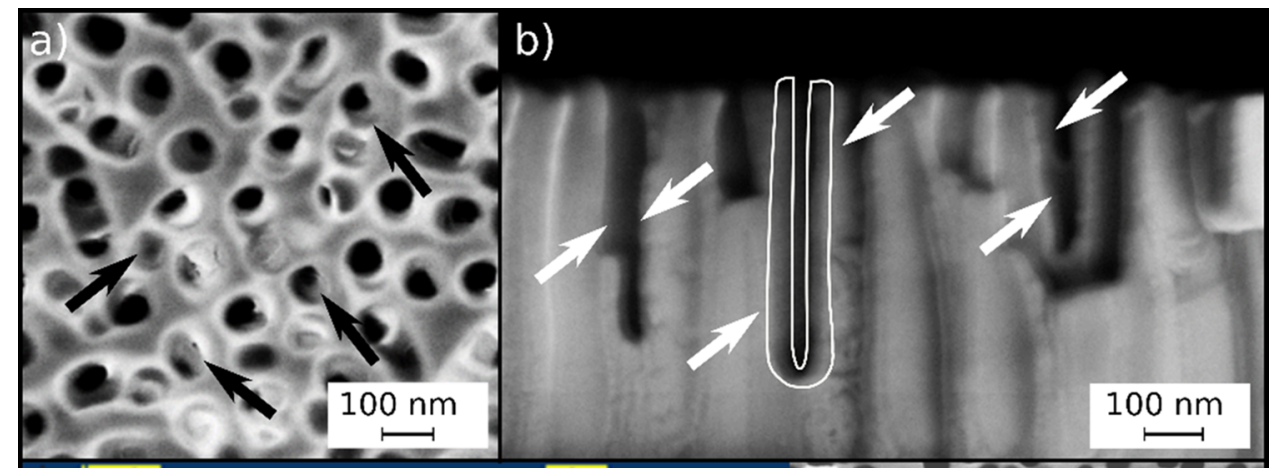

c)
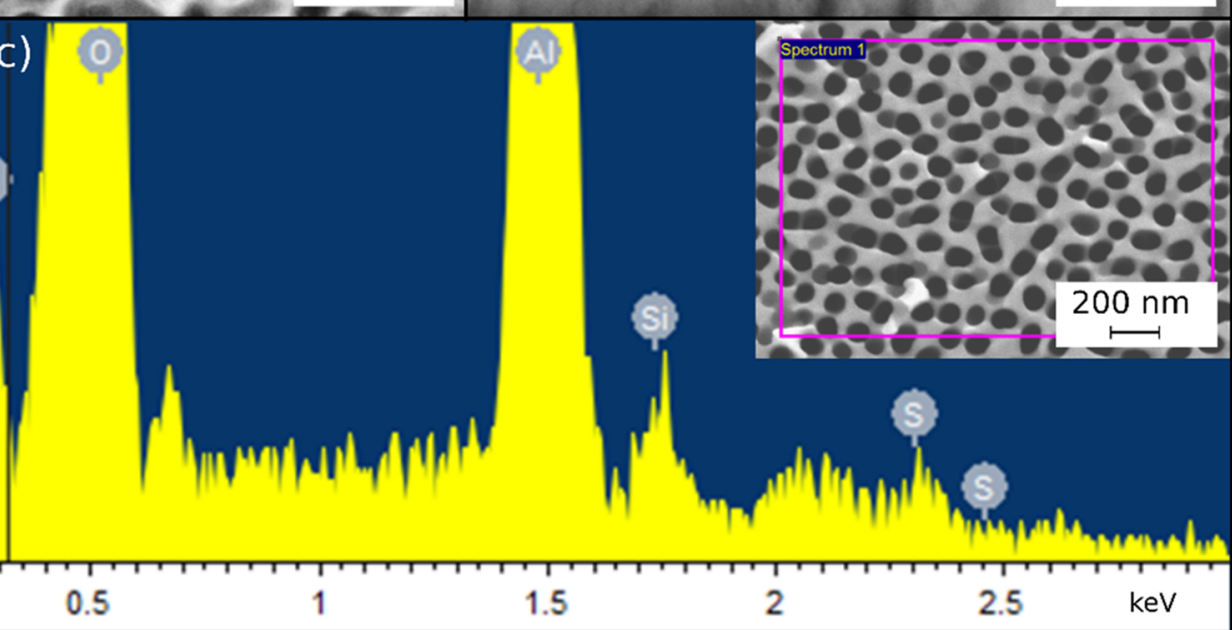

d)
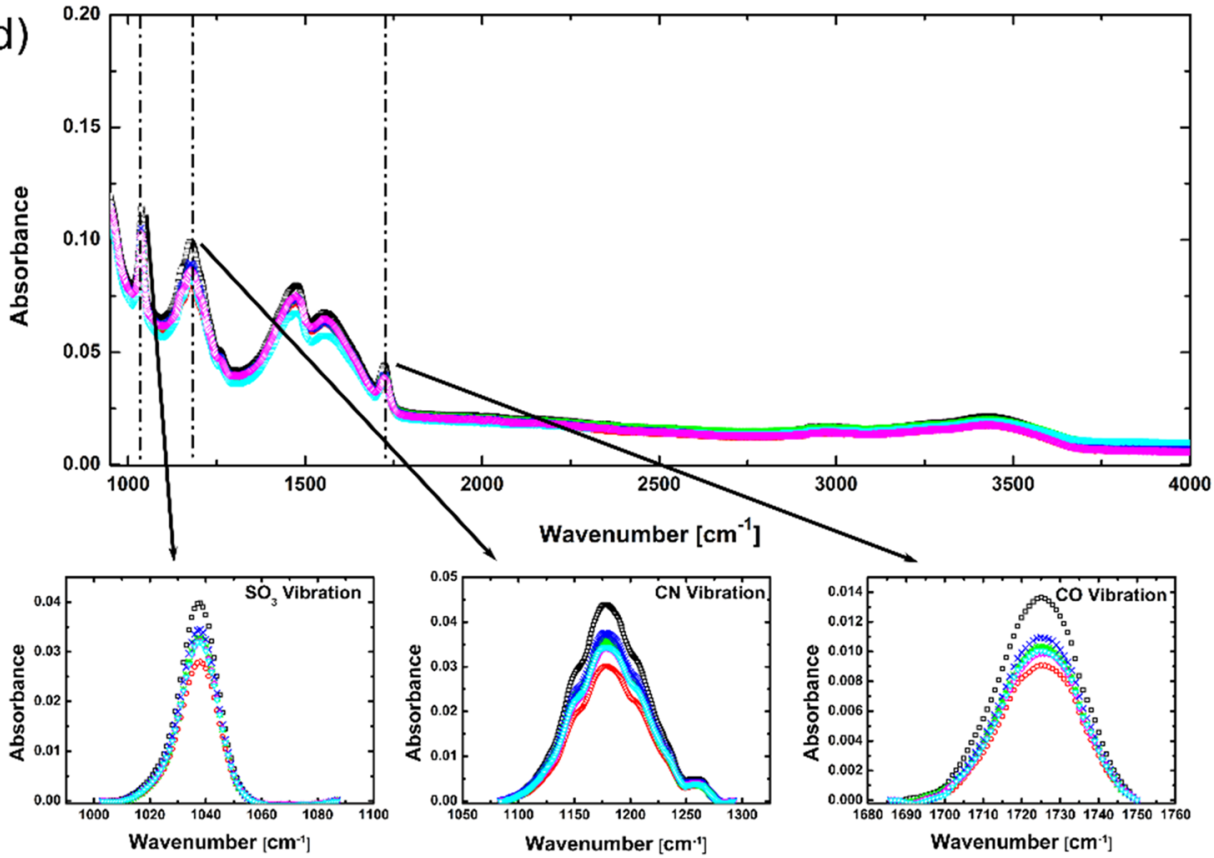
Fig. 4 AFM images of the SPEcoated AAO sample: $\mathbf{a}$ in air, $\mathbf{b}$ in deionized water

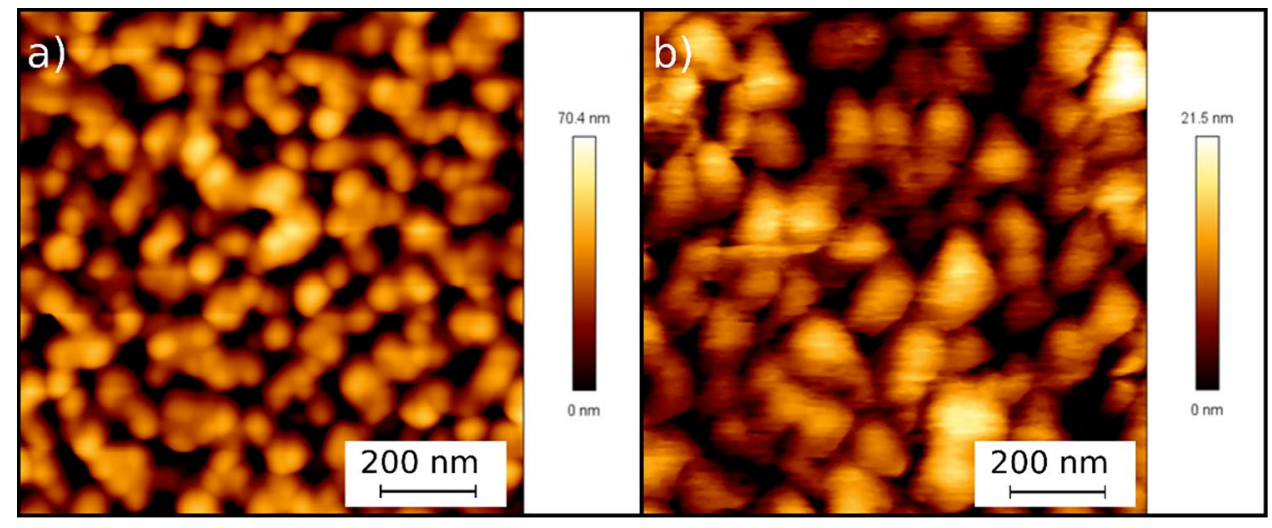

\begin{tabular}{|c|c|c|c|c|c|c|c|c|}
\hline & Avg & St. Dev & Avg & St. Dev & Avg & St. Dev & Avg & St. Dev \\
\hline \multicolumn{9}{|c|}{ (a) Glass substrate } \\
\hline$h(\mathrm{~nm})$ & 100.10 & 0.08 & 300.15 & 0.11 & 500.31 & 0.13 & 700.30 & 0.15 \\
\hline$P(\mathrm{mN})$ & 0.86 & 0.09 & 6.96 & 0.48 & 19.75 & 0.99 & 39.23 & 1.59 \\
\hline$E(\mathrm{GPa})$ & 75.24 & 3.39 & 81.29 & 1.19 & 78.31 & 0.89 & 74.56 & 0.90 \\
\hline$H(\mathrm{GPa})$ & 2.29 & 0.27 & 3.71 & 0.33 & 4.57 & 0.34 & 5.10 & 0.34 \\
\hline \multicolumn{9}{|c|}{ (b) AAO film on glass substrate } \\
\hline$h(\mathrm{~nm})$ & 50.09 & 0.05 & 100.11 & 0.09 & 150.13 & 0.10 & 200.16 & 0.09 \\
\hline$P(\mathrm{mN})$ & 0.12 & 0.02 & 0.41 & 0.04 & 0.76 & 0.08 & 1.16 & 0.10 \\
\hline$E(\mathrm{GPa})$ & 27.86 & 3.41 & 33.84 & 2.90 & 37.90 & 2.34 & 41.31 & 2.08 \\
\hline$H(\mathrm{GPa})$ & 0.83 & 0.16 & 1.10 & 0.10 & 1.12 & 0.13 & 1.08 & 0.10 \\
\hline \multicolumn{9}{|c|}{ (c) SPE-AAO film on glass substrate } \\
\hline$h(\mathrm{~nm})$ & 50.10 & 0.10 & 100.16 & 0.09 & 150.17 & 0.07 & 200.22 & 0.12 \\
\hline$P(\mathrm{mN})$ & 0.12 & 0.04 & 0.38 & 0.09 & 0.71 & 0.11 & 1.14 & 0.16 \\
\hline$E(\mathrm{GPa})$ & 27.87 & 7.24 & 34.72 & 6.65 & 39.48 & 4.50 & 42.93 & 4.33 \\
\hline$H(\mathrm{GPa})$ & 0.83 & 0.31 & 1.01 & 0.25 & 1.02 & 0.16 & 1.05 & 0.15 \\
\hline
\end{tabular}

Table 1 Experimental data of the elastic modulus $(E)$ and hardness $(H)$ values obtained via nanoindentation testing for different depth $(h)$ and load $(P)$ values of a glass substrate, AAO thin film and SPE-coated AAO thin film, both on glass substrate

Table 2 Comparison of the modulus and hardness obtained from experiments in dry and wet conditions and compared with FEA

\begin{tabular}{|c|c|c|c|c|c|c|}
\hline & \multirow[t]{2}{*}{$\mathrm{h}_{\max }(\mathrm{nm})$} & \multirow[t]{2}{*}{ Cond. } & \multicolumn{2}{|c|}{ Elastic modulus (GPa) } & \multicolumn{2}{|c|}{ Hardness (GPa) } \\
\hline & & & Exp & FEA & Exp & FEA \\
\hline (a) Glass substrate & 793 & Dry & 73.10 & 73.50 & 5.16 & 5.18 \\
\hline \multirow[t]{2}{*}{ (b) AAO-glass } & \multirow[t]{2}{*}{125} & Dry & 35.80 & \multirow[t]{2}{*}{35.65} & 1.13 & \multirow[t]{2}{*}{1.16} \\
\hline & & Wet & 33.77 & & 1.00 & \\
\hline \multirow[t]{2}{*}{ (c) SPE-AAO-glass } & \multirow[t]{2}{*}{125} & Dry & 37.10 & \multirow[t]{2}{*}{35.13} & 1.01 & \multirow[t]{2}{*}{1.15} \\
\hline & & Wet & 34.50 & & 1.00 & \\
\hline
\end{tabular}

observe the property distribution with respect to the sample topography. From the first observations, a good correlation is noticed between the hardness and elastic modulus in term of the peak values. In addition, the mapping shows a close to homogenous distribution of the properties on the coated and the non-coated sample. Small differences are noticed from one point to another, probably accruing from the porous structure the AAO film, and the distribution of the polymer coating for the SPE-coated sample.

\section{Microscopy of the indented layers}

Top-view secondary electron (SE) micrographs comparing indentations in AAO and AAO-SPE are shown in Fig. 6. 
(a)

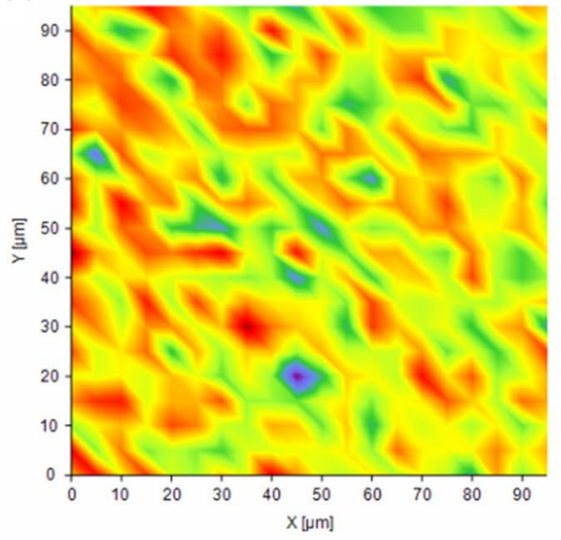

(c)

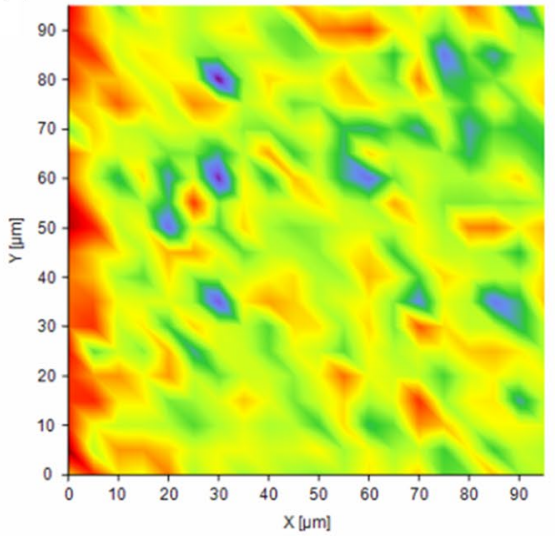

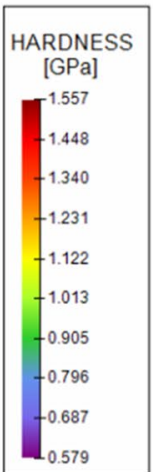

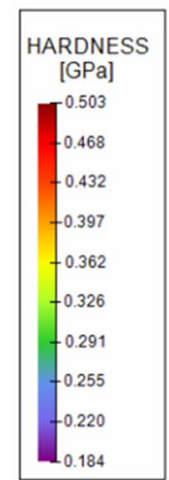

(b)

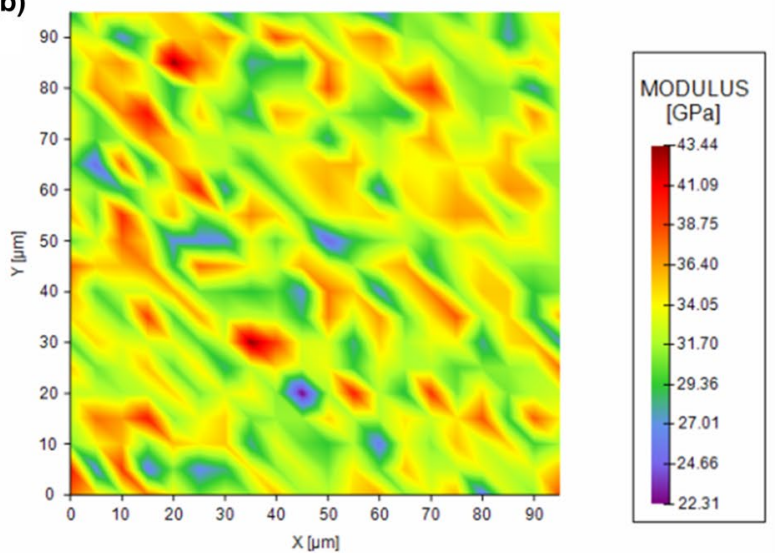

(d)

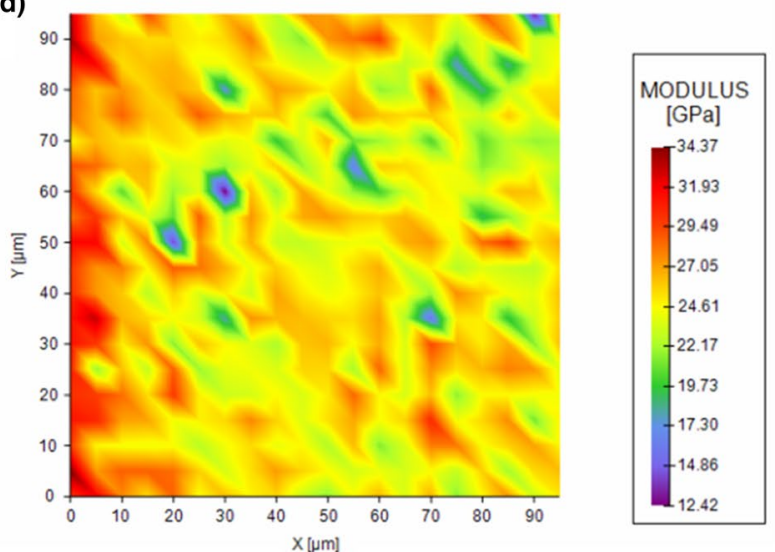

Fig. 5 Hardness and elastic modulus maps of non-coated AAO thin film (a, b) and SPE-coated AAO thin film (c, d)

It is interesting to note that in both cases the indentations result in the smearing of the pores without the appearance, or at least limited, cracking which confers to the indentation a sort of plasticity. Such a behavior has been previously observed for AAO of different pore sizes and percentage porosity on aluminum, although the testing conditions were different from the one considered in this work (Vojkuvka et al. 2012). The high-resolution micrograph of bare AAO shows only compressed material with eventually deformed pores and no cleavage cracks in the center of the indentation. This behavior is more pronounced in SPE coated AAO, presumably because of the presence of the polymer layer.

\section{Modeling}

The results obtained from the modeling of the nanoindentation process on glass and AAO thin films are shown in Table 2. The tip used in the modeling was modified to ensure that the results are consistent with the experimental ones and the load-depth curve is close to the one of the fused silica, as shown in Fig. 1. For a fixed value of the indentation depth for the three samples (notice that the depth in the AAO films is limited to approximately $30 \%$ of the film thickness which should preclude any substrate effect), the elastic modulus and the hardness from the simulation are in good agreement with the measured ones. However, it can be noticed that the hardness obtained from the simulation is slightly higher than the one obtained from the nanoindentation experiment. This might arise from inhomogeneity of the SPE coating, but also from the model which, for the sake of simplicity (the contact between the tip and the polymer is avoided because the properties of the polymer are not known), stipulates that only the pore walls are coated with SPE.

The stress and strain distributions are presented in Fig. 7. The strain distributions are found to take highest values in the coated AAO film, and essentially in the polymeric film, 


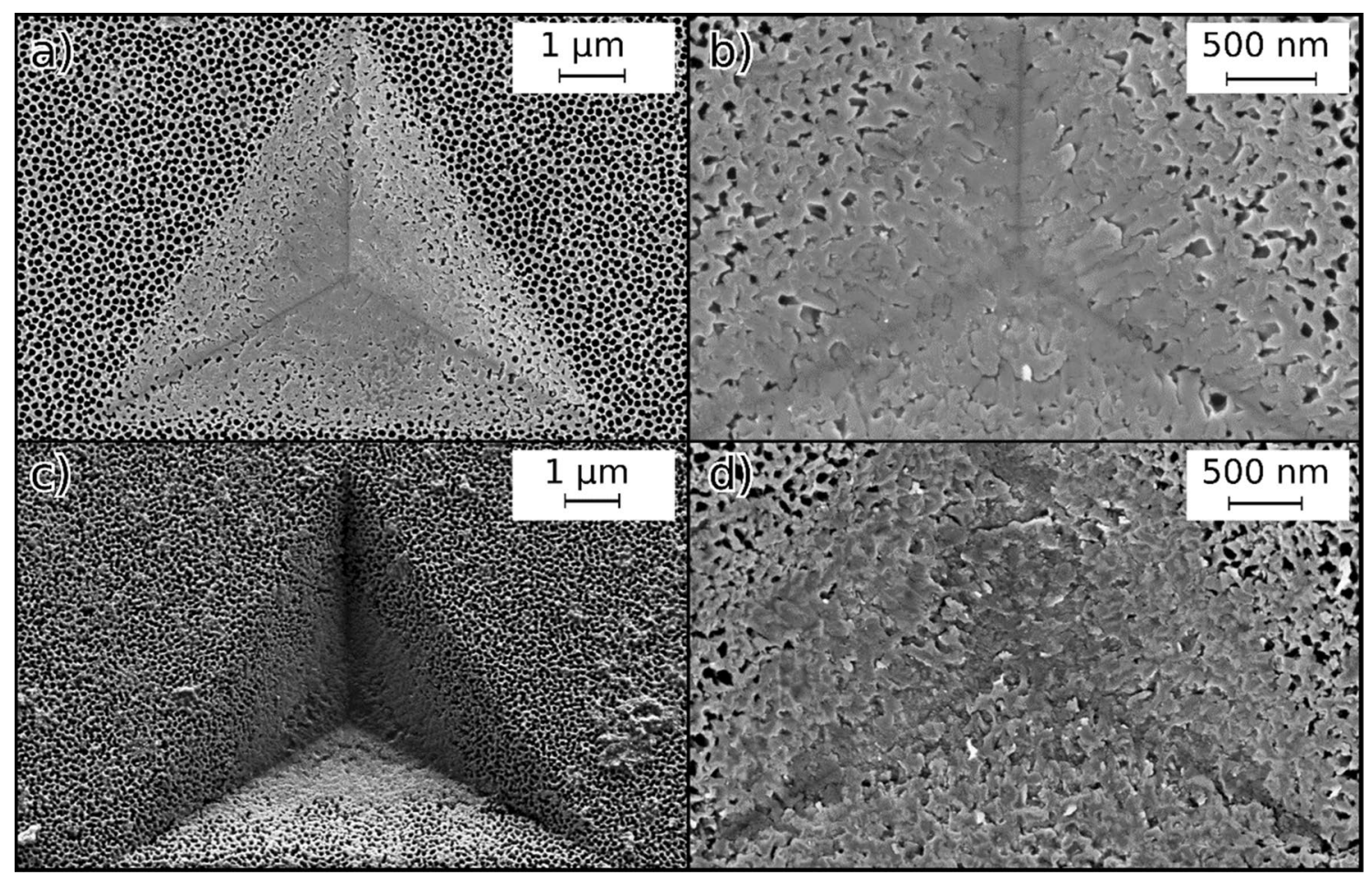

Fig. 6 Top-view SEM images with different magnifications of the indentations in non-coated AAO films (a, b), and SPE-coated AAO (c, d). Notice the higher degree of "smearing" in $(\mathbf{c}, \mathbf{d})$ due to the presence of the polymer film

obviously due to its low stiffness. In comparison, low strain values are noticed in the AAO film with a maximum of $5.2 \%$ that is slightly lower than that of the glass substrate, probably because of the presence of the pores. Noteworthy is the similarity of the simulation results and the top-view microscopic images of the nanoindentation depicted in Fig. 6 with compression of the pore walls, leading to closure of the pores. In cross section, there is also a large similarity between simulation and deformation behavior qualitatively depicted in a cross-section of a scratch (see Fig. 9c, d below), where buckling of the pore walls is clearly visible.

The stress distribution in the AAO thin films shows a completely different picture than what is observed in the glass plate. While the stress field in the glass plate is almost spherical in its expansion, with maximum values underneath the nanoindenter tip, the presence of the pores in AAO thin films seems to limit the magnitude of stress. The stress distributions take a semispherical shape with field maximum under the tip, weakly radiating in the neighboring areas of the AAO films.

Figure 7 also shows that higher stress values are obtained in the AAO pore walls of the SPE-coated AAO thin film, due to the presence of the polymer inside the pore's structures. Finally, a close look at the substrate underneath the AAO films reveals semispherical stress and strain distributions, although with substantially lower magnitudes than in the AAO films.

\section{Nano-scratch testing}

Nano-scratch testing was performed on the SPE-coated and non-coated AAO thin films using different loads. The $200 \mu \mathrm{m}$ scratches start at $0 \mathrm{mN}$ and end at the preset maximum load of $2 \mathrm{mN}$. The AAO samples were tested in dry and wet conditions. From the results, shown in Fig. 8, similar scratch curves were obtained for the dry SPE-coated AAO and dry/wet non-coated AAO thin films, with the scratch reaching the critical index at the same load value and a depth of around $350 \mathrm{~nm}$. For the wet SPE-coated AAO thin film, it is clearly noticed that the critical load is reached slightly faster than in the dry condition which might be due to polymer swelling (see also the AFM images above).

In Fig. 9a, b, SEM images of the scratches on both coated and non-coated samples are presented. In both cases the upper layer is sheared by the indenter, leading to broken pore walls and the smearing of the porous structure with, however, roughly any pile-up. The existence of the SPE-polymer has the effect of a stronger smearing of the upper-layer (compare the outlined areas in Fig. 9a, b) which is probably 
Fig. 7 Equivalent elastic strain $(\mu \mathrm{m} / \mu \mathrm{m})$ distributions at $125 \mathrm{~nm}$ depth in glass (a), AAO on glass (b) and SPE-coated AAO on glass (c). Equivalent (vonMises) stress (MPa) distributions at $125 \mathrm{~nm}$ depth in glass (d), AAO on glass (e) and SPEcoated AAO on glass $(\mathbf{f})$

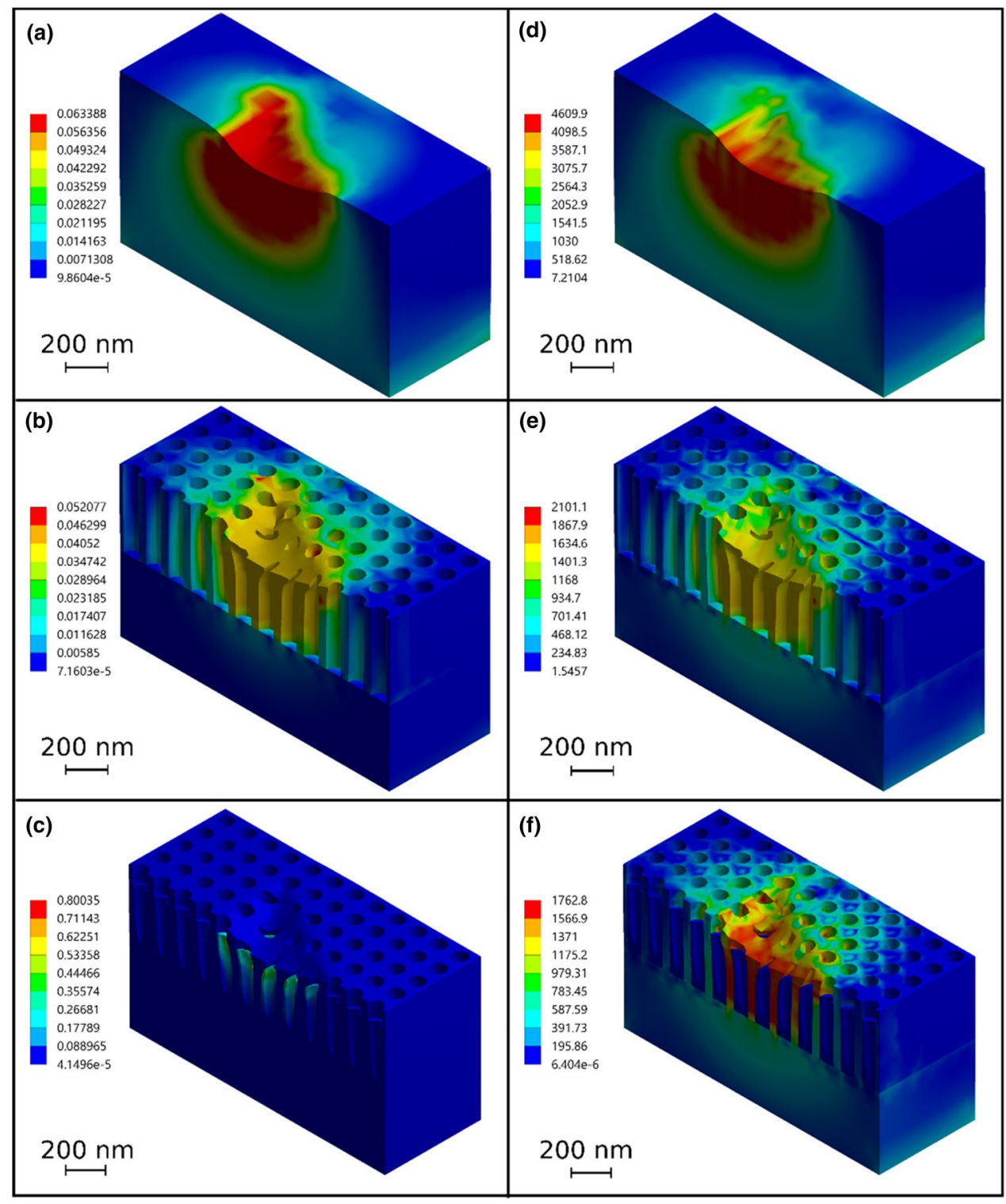

due to the plastifying effect of the polymer. Further, the polymer is expected to remain on the surface thus conferring the anti-biofouling functionality to the surface, even after a relatively deep scratch, and this endows these layers with a kind of self-healing property (Es-Souni et al. 2019). In Fig. S4 (Supplementary Material), the cross-profile of the scratch is plotted with respect to the position of the scratch, which is fixed at 0.8 fraction of the scratch length. Similar cross profile curves were obtained with small differences between the coated and non-coated AAO sample, in both dry and wet conditions.
SEM cross-sections through scratches that were performed at a maximum normal load of $2.5 \mathrm{mN}$ are presented in Fig. 9c, d. As mentioned above, deformation of the films is affected by buckling of the pore walls. However, while in the case of the non-coated films, breaking of the pore walls is a dominant damage occurrence (Fig. 9c, delineated area), the coated films, in contrast, hardly show broken pore walls. A close look at Fig. 9d (delineated area), suggests that the polymeric film acts as though it is gluing/repairing the damages to the pore walls. This supports the results depicted above for the morphology of the nanoindentation 
Fig. 8 Scratch profile for $\mathbf{a}$ AAO on glass and $\mathbf{b}$ SPEcoated AAO on glass

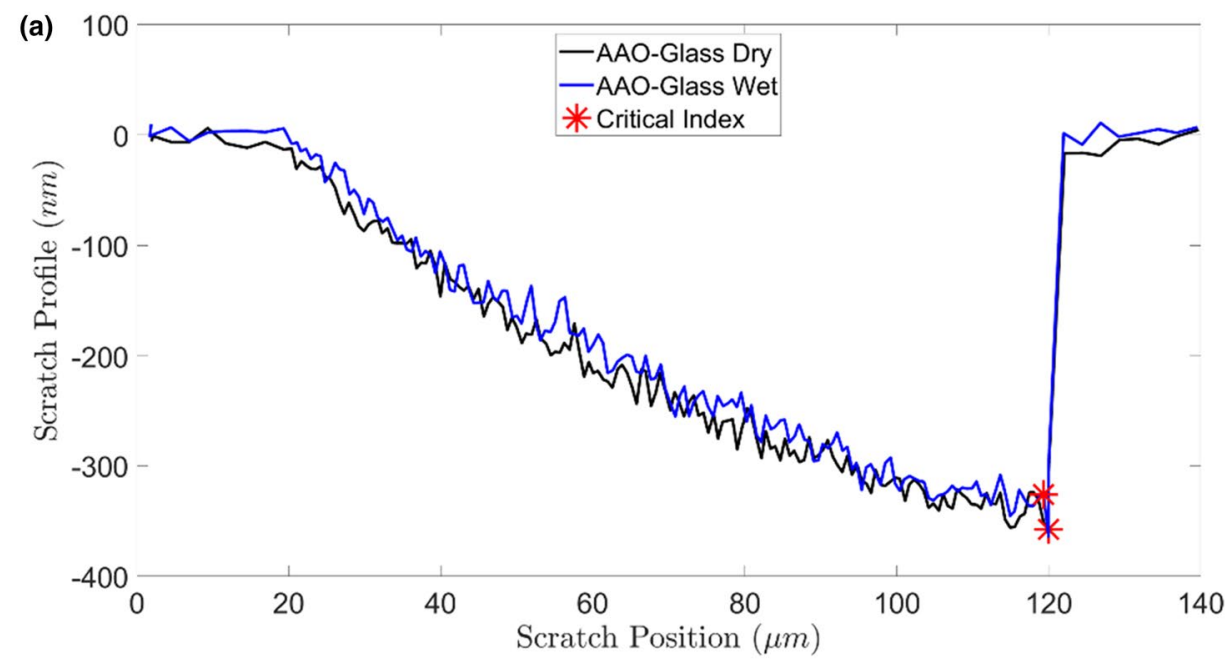

(1)

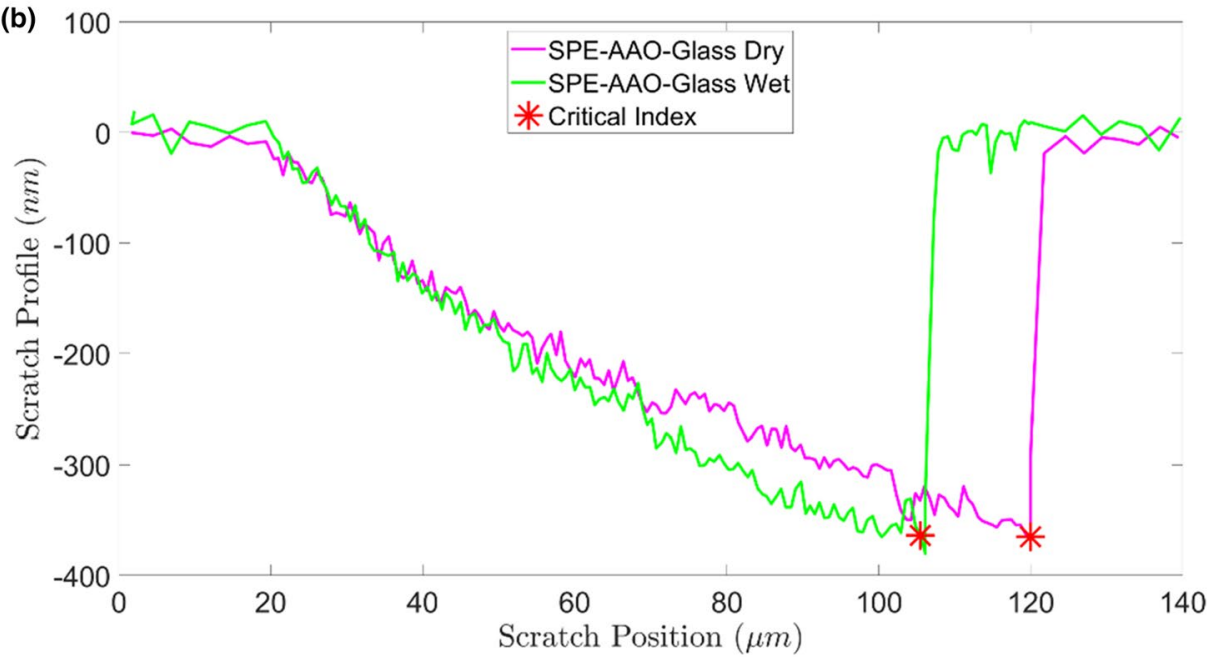

(Fig. 6) and the scratch surface (Fig. 9a, b). More SEM images of the middle part of the scratch are presented in Fig. S5 (Supplementary Material) with little difference in the scratch morphology.

\section{Conclusions}

In the present work, porous anodic aluminum oxide thin films are first processed on glass substrates and subsequently photo-grafted with a zwitterionic anti-biofouling polymer (SPE). This with the aim of fabricating scratchresistant, transparent anti-biofouling films. Morphological and nanomechanical studies together with FEA modeling are conducted to understand the behavior of the films. The following conclusions may be drawn:
- The polymer forms a thin layer of approximately $20 \mathrm{~nm}$ on the pore walls and, when soaked in in deionized water, the pore diameter changes due to swelling of the polymer

- The average nanomechanical properties, elastic modulus and hardness, of coated and non-coated AAO films are very similar. This is explained in terms of the low volume fraction of the polymer and its weakness in comparison to the AAO film. Property mapping show an almost homogeneous property distribution

- Nanomechanical testing in wet and dry condition yields slightly higher elastic modulus and hardness in the dry condition

- FEA modeling using an optimized 3D-model yields very close results to the experimental ones

- The deformation behavior of the AAO-films obtained with FEA modeling is very well reflected in the microscopic examination of deformed films 


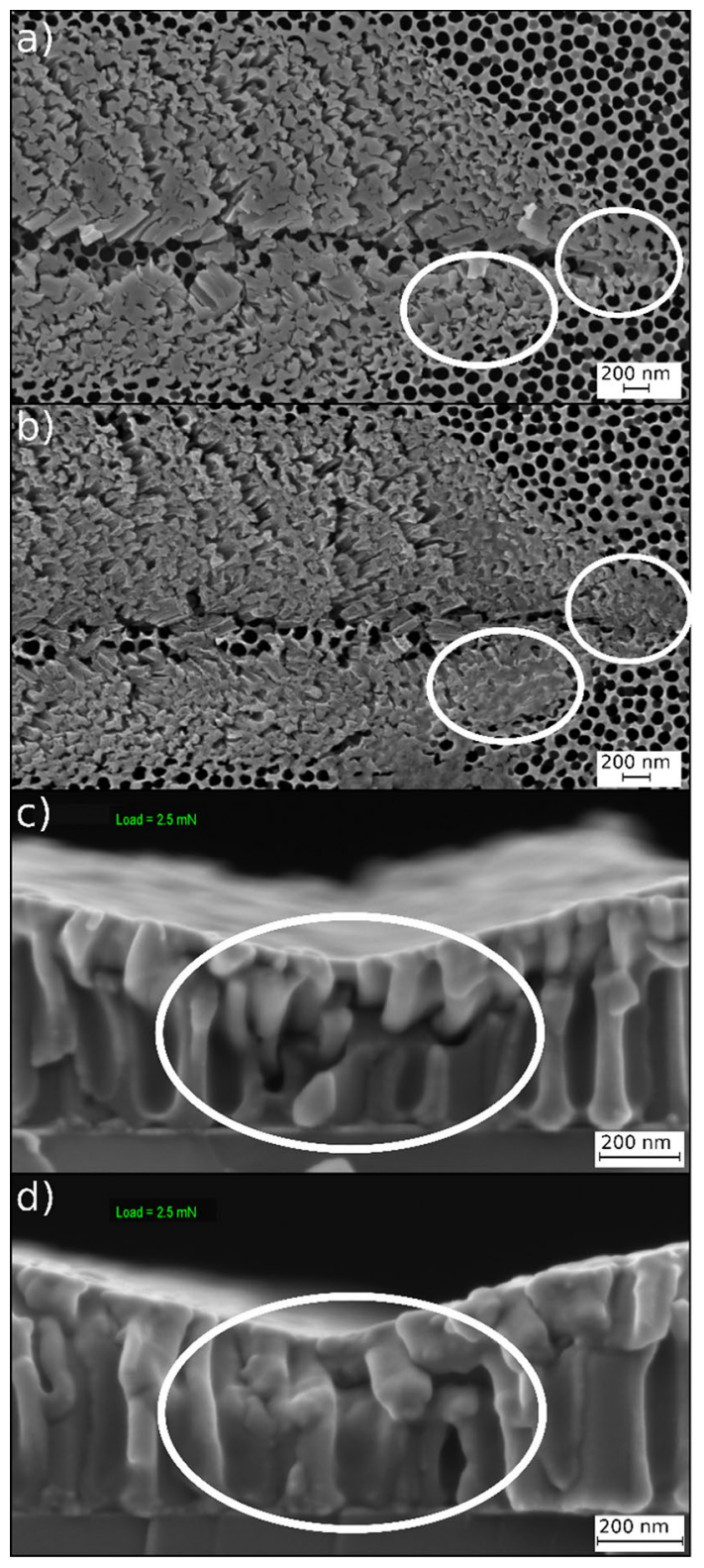

Fig. 9 SEM images near the end of the scratch position for (a) AAO on glass and (b) SPE-coated AAO on glass. SEM cross-sections through scratches in non-coated AAO (c) and SPE-coated AAO (d) thin films performed at a maximum normal load of $2.5 \mathrm{mN}$. The delineated areas compare the behaviors of coated and non-coated AAO. Notice that the pore walls are formally "glued" to each others in $(\mathbf{d})$

- Nano-scratch testing of both coated and non-coated AAO films shows no pile-up or delamination of the films

- The SPE-coated AAO film shows a different damage picture than the coated one. Specifically, the polymer layer seem to act similarly to a glue, preventing complete braking of the walls.
Acknowledgements Open Access funding provided by Projekt DEAL. Financial funding of this project is provided by the German Federal Ministry of Economy, Energy and Transport, Project \#0325915F.

\section{Compliance with ethical standards}

Conflict of interest On behalf of all authors, the corresponding author states that there is no conflict of interest.

Open Access This article is licensed under a Creative Commons Attribution 4.0 International License, which permits use, sharing, adaptation, distribution and reproduction in any medium or format, as long as you give appropriate credit to the original author(s) and the source, provide a link to the Creative Commons licence, and indicate if changes were made. The images or other third party material in this article are included in the article's Creative Commons licence, unless indicated otherwise in a credit line to the material. If material is not included in the article's Creative Commons licence and your intended use is not permitted by statutory regulation or exceeds the permitted use, you will need to obtain permission directly from the copyright holder. To view a copy of this licence, visit http://creativecommons.org/licenses/by/4.0/.

\section{References}

Alaboodi AS, Hussain Z (2019) Finite element modeling of nanoindentation technique to characterize thin film coatings. J King Saud Univ Eng Sci 31:61-69. https://doi.org/10.1016/j.jksue s.2017.02.001

Balde M, Vena A, Sorli B (2015) Fabrication of porous anodic aluminium oxide layers on paper for humidity sensors. Sens Actuators B Chem 220:829-839. https://doi.org/10.1016/j.snb.2015.05.053

Berger N, Es-Souni M (2016a) Understanding and shaping the morphology of the barrier layer of supported porous anodized alumina on gold underlayers. Langmuir 32:6985-6990 https://doi. org/10.1021/acs.langmuir.6b01732

Berger N, Habouti S, Rubahn HG, Es-Souni M (2016b) On-substrate fabrication of porous $\mathrm{Al}_{2} \mathrm{O}_{3}$ templates with tunable pore diameters and interpore distances. Appl Phys A Mater Sci Process 122:1-7. https://doi.org/10.1007/s00339-016-9729-z

Choudhary RK, Mishra P, Kain V et al (2015) Scratch behavior of aluminum anodized in oxalic acid: effect of anodizing potential. Surf Coat Technol 283:135-147. https://doi.org/10.1016/j.surfc oat.2015.10.042

Chung CK, Tsai CH, Hsu CR et al (2017) Impurity and temperature enhanced growth behaviour of anodic aluminium oxide from AA5052 Al-Mg alloy using hybrid pulse anodization at room temperature. Corros Sci 125:40-47. https://doi.org/10.1016/j. corsci.2017.05.027

Dai J, Singh J, Yamamoto N (2017) The effect of nano pore size and porosity on deformation behaviors of anodic aluminum oxide membranes. pp 218-229 Paper presented at SAMPE Seattle 2017 Conference, Seattle, United States

Es-Souni M, Wassel E, Dietze M et al (2019) Processing of nanotubes on NiTi-shape memory alloys and their modification with photografted anti-adhesive polymer brushes. Towards smart implant surfaces. Materials and design, vol 182, pp 108031108042. https://doi.org/10.1016/j.matdes.2019

Fang T-H, Wang TH, Kang S-H (2009) Nanomechanical and surface behavior of polydimethylsiloxane-filled nanoporous anodic alumina. J Mater Sci 44:1588-1593. https://doi.org/10.1007/s1085 3-008-3232-7

Hemmouche L, Chicot D, Amrouche A et al (2013) An analysis of the elastic properties of a porous aluminium oxide film by means of 
indentation techniques. Mater Sci Eng A 585:155-164. https:// doi.org/10.1016/j.msea.2013.07.054

Hu Z (2017) Characterization of materials, nanomaterials, and thin films by nanoindentation. In: Thomas S, Thomas R, Zachariah AK, Mishra RK (eds) Microscopy methods in nanomaterials characterization. Elsevier, Amsterdan, NL, pp 165-239

Hu Z, Shrestha M, Fan QH (2016) Nanomechanical characterization of porous anodic aluminum oxide films by nanoindentation. Thin Solid Films 598:131-140. https://doi.org/10.1016/j. tsf.2015.11.073

Khan NS, Islam S, Gul T et al (2018) Thin film flow of a second grade fluid in a porous medium past a stretching sheet with heat transfer. Alex Eng J 57:1019-1031. https://doi.org/10.1016/j. aej.2017.01.036

Ko SH, Lee DW, Jee SE et al (2005) Mechanical properties and residual stress measurements in anodic aluminium oxide structures using nanoindentation. Glass Phys Chem 31:356-363 https://doi. org/10.1007/s10720-005-0069-x

Laghrissi A, Es-Souni M (2019) Porous PtPd alloy nanotubes: towards high performance electrocatalysts with low Pt-loading. Catal Sci Technol 9:4355-4364. https://doi.org/10.1039/c9cy01145e

Li X, Bhushan B (2002) A review of nanoindentation continuous stiffness measurement technique and its applications. Mater Charact 48:11-36. https://doi.org/10.1016/S1044-5803(02)00192-4

Mallikarjunachari G, Ghosh P (2016) Analysis of strength and response of polymer nano thin film interfaces applying nanoindentation and nanoscratch techniques. Polymer (Guildf) 90:53-66. https://doi. org/10.1016/j.polymer.2016.02.042

Mijangos C, Hernández R, Martín J (2016) A review on the progress of polymer nanostructures with modulated morphologies and properties, using nanoporous AAO templates. Prog Polym Sci 54-55:148-182. https://doi.org/10.1016/j.progpolyms ci.2015.10.003

Oliver WC, Pharr GM (2004) Measurement of hardness and elastic modulus by instrumented indentation: advances in understanding and refinements to methodology. J Mater Res 19:3-20. https://doi. org/10.1557/jmr.2004.19.1.3

Oliver WC, Pharr GM (1992) An improved technique for determining hardness and elastic modulus using load and displacement sensing indentation experiments. J Mater Res 7:1564-1583. https://doi. org/10.1557/JMR.1992.1564

Ozmetin AE, Sahin O, Ongun E, Kuru M (2015) Mechanical characterization of $\mathrm{MgB} 2$ thin films using nanoindentation technique. J Alloy Compd 619:262-266. https://doi.org/10.1016/j.jallc om.2014.09.015

Sharma K, Islam SS (2016) Optimization of porous anodic alumina nanostructure for ultra high sensitive humidity sensor. Sens
Actuators B Chem 237:443-451. https://doi.org/10.1016/j. snb.2016.06.041

Szuwarzyński M, Zaraska L, Sulka GD, Zapotoczny S (2013) Pulsatile releasing platform of nanocontainers equipped with thermally responsive polymeric nanovalves. Chem Mater 25:514-520. https ://doi.org/10.1021/cm303930y

Tsyntsaru N, Kavas B, Sort J et al (2014) Mechanical and frictional behaviour of nano-porous anodized aluminium. Mater Chem Phys 148:887-895. https://doi.org/10.1016/j.matchemphys.2014.08.066

Vojkuvka L, Santos A, Pallarès J et al (2012) On the mechanical properties of nanoporous anodized alumina by nanoindentation and sliding tests. Surf Coat Technol 206:2115-2124. https://doi. org/10.1016/j.surfcoat.2011.09.040

Wang B, Fei GT, Wang M et al (2007) Preparation of photonic crystals made of air pores in anodic alumina. Nanotechnol 18:365601365605. https://doi.org/10.1088/0957-4484/18/36/365601

Wassel E, Es-Souni M, Laghrissi A et al (2018) Scratch resistant non-fouling surfaces via grafting non-fouling polymers on the pore walls of supported porous oxide structures. Materials and design, vol 163, pp 107542-107552. https://doi.org/10.1016/j. matdes. 2018

Wen W, Becker AA, Sun W (2017) Determination of material properties of thin films and coatings using indentation tests: a review. J Mater Sci 52:12553-12573. https://doi.org/10.1007/s1085 3-017-1348-3

Wojciechowski J, Szubert K, Peipmann R et al (2016) Anti-corrosive properties of silane coatings deposited on anodised aluminium. Electrochim Acta 220:1-10. https://doi.org/10.1016/j.elect acta.2016.10.080

Xie Y, Kocaefe D, Chen C, Kocaefe Y (2016) Review of research on template methods in preparation of nanomaterials. J Nanomater 2016:1-10. https://doi.org/10.1155/2016/2302595

Yabuki A, Nagayama Y, Fathona IW (2019) Porous anodic oxide film with self-healing ability for corrosion protection of aluminum. Electrochim Acta 296:662-668. https://doi.org/10.1016/j.elect acta.2018.11.119

Zechner J, Mohanty G, Frantz C et al (2014) Mechanical properties and interface toughness of metal filled nanoporous anodic aluminum oxide coatings on aluminum. Surf Coat Technol 260:246-250 https://doi.org/10.1016/j.surfcoat.2014.08.086

Publisher's Note Springer Nature remains neutral with regard to jurisdictional claims in published maps and institutional affiliations. 